Revista de Filosofía

ISSN: 0034-8244

http://dx.doi.org/10.5209/resf.72291

\title{
La risa de Zaratustra
}

José Emilio Esteban Enguita ${ }^{1}$

Recibido: 13 de marzo de 2018 / Aceptado: 7 de mayo de 2019

Resumen. El propósito de este artículo es mostrar el sentido de la risa del filósofo Zaratustra en la obra de Friedrich Nietzsche. Su risa expresa una actitud filosófica y posee tres características: es signo de la sabiduría trágica, síntoma de una forma de vida saludable y una herramienta para la crítica de los ideales que dañan la vida. Concluimos el artículo considerando que la risa y la comedia es el necesario punto de llegada de la concepción dionisíaca del mundo.

Palabras clave: Nietzsche; Zaratustra; risa; actitud filosófica; vida; comedia.

\section{[en] Zarathustra's laugh}

Abstract. This paper aims to show the meaning of the laughter of the philosopher Zarathustra in the work of Friedrich Nietzsche. His laughter expresses a philosophical attitude and has three characteristics: it is a sign of tragic wisdom, a symptom of a healthy lifestyle and a tool for criticising the ideals that damage life. We conclude the article considering that laughter and humour are the necessary point of arrival of the Dionysian conception of the world.

Keywords: Nietzsche; Zaratustra; laughter; philosophical attitude; life; humour.

Sumario: 1. La risa de un filósofo llamado Zaratustra; 2. La risa como signo de sabiduría; 3. La risa como síntoma de una forma de vida; 4 . La risa como medio de destrucción; 5. Incipit tragoedia, incipit parodia: un modo de concluir; 6 . Referencias bibliográficas.

Cómo citar: Esteban Enguita, J.E. (2020): "La risa de Zaratustra”, en Revista de Filosofía 45 (2), 285299.

$1 \quad$ Facultad de Filosofía y Letras

Departamento de Filosofía

Universidad Autónoma de Madrid

j.emilio.esteban@uam.es 
Un texto de Heidegger se intitula Wer ist Nietzsches Zarathustra? ¿Quién es el Zaratustra de Nietzsche?). En él responde a lo que se pregunta en el título: Zaratustra es el portavoz de la vida, del sufrimiento y del círculo; como portavoz, "habla por adelantado" y lleva la voz cantante, y, sobre todo, da razones y aclara tanto de lo que habla como del para qué lo hace ${ }^{2}$. Zaratustra, además, en palabras certeras de sus animales, es el maestro del eterno retorno ${ }^{3}$. Sin duda, Zaratustra es lo que dice Heidegger, pero también, sin duda, el quién de Zaratustra no se agota en absoluto con ese decir, porque el portavoz de todo aquello y el maestro del eterno retorno es alguien que no para de reír. De la risa de Zaratustra nada dice Heidegger, razón por la cual su interpretación se nos revela como insuficiente. Que la "historia del Ser" sea inmune a cualquier tipo de infección cómica expresa de forma meridiana la parcialidad de la exégesis heideggeriana de la figura de Zaratustra y del pensamiento de Nietzsche. En el retrato de Heidegger, el maestro del eterno retorno, como filósofo, muestra esa gravedad que se compadece mal con la ligereza de los movimientos y el tono de los discursos de Zaratustra, quien, por encima de todas las cosas, ha de bailar y reír. La respuesta a la pregunta por la identidad de Zaratustra, dando por hecho que representa, o pretende representar, un nuevo tipo de filósofo, ha de incluir a la risa como uno de sus rasgos distintivos e imprescindibles. En este sentido, Zaratustra no es sólo el filósofo valiente y veraz por excelencia, sino que, además, y no como un aspecto subsidiario de esas o de otras características, es el filósofo que ríe, que no para de reír y de carcajearse. La pregunta "¿Quién es el Zaratustra de Nietzsche?" demanda una respuesta que se tome muy en serio su risa, lo que significa que no puede ser satisfactoriamente respondida si uno no es capaz de responder esta otra: ¿qué significa la risa de Zaratustra?

\section{La risa de un filósofo llamado Zaratustra}

La broma, la parodia, la burla, el sarcasmo, la ironía, todos afines a la risa, la sonrisa o la carcajada proliferan en momentos capitales y en muchos de los rincones de Así habló Zaratustra. Zaratustra, en boca de Nietzsche, significa, para empezar, una suerte de inversión cómica: el primero -Zoroastro- que transformó la moral en metafísica, comprendiendo que sólo así se garantizaba el supremo poder que depende de las palabras "bien" y "mal", ha de ser también el primero en reconocer su error, disfrazándose de bufón que hace payasadas, sí, pero que está hermanado con la verdad ${ }^{4}$. Además, es el primer sabio inmoralista ${ }^{5}$, haciendo sangre mediante la burla y la risa maliciosa de la candidez de los hasta ahora llamados "buenos", esos perfectos mentirosos que pudren la vida de forma tan implacable como inocente. Para terminar, es el discípulo más aventajado de Dioniso y, por ello, el Anticristo ${ }^{6}$,

Heidegger (1954), p.98.

Heidegger (1954), p. 101.

4 Nietzsche (1988), VI, p. 367. Las traducciones empleadas provienen de las ediciones de Nietzsche en castellano dirigidas por Diego Sánchez Meca, tituladas Fragmentos póstumos y Obras completas, y publicadas en la Editorial Tecnos.

5 Nietzsche (1988), VI, p. 370.

6 "La figura que se caracteriza propiamente por su radical extrañeza a la risa no puede ser más que el gran adversario de Zaratustra. El Anticristo de Nietzsche es aquel que ríe. Cada carcajada es un desvanecerse del ser cristianos." Cacciari (1994), p. 110. 
el encarnizado enemigo del Crucificado, que desenmascara las vergüenzas del cristianismo, su mendacidad constitutiva y su idea de Dios, la más dañina para la vida $^{7}$. La parodia, la ironía y el sarcasmo colorean cada cita, alusión o referencia de esta obra al mensaje cristiano, y la risa de Zaratustra anuda en su seno tanto la expresión del vigor de su cuerpo y de su alma, como la fuerza negadora dirigida contra los Evangelios. También, aunque no sólo ni fundamentalmente, este singular libro es un anti-evangelio, $\mathrm{o}$, mejor dicho, la transvaloración en gran medida humorística de los valores cristianos llevada a cabo por ese cómico y bailarín que responde al nombre de Zaratustra.

La risa de Zaratustra es una cuestión filosófica porque sus acciones y discursos no son los de un santo, ni los de un hombre religioso, ni los de un poeta, sino la anticipación del filósofo del porvenir, de un nuevo tipo filosófico, pues consabido es que hasta ahora, a juicio de Nietzsche, no ha existido un verdadero filósofo sobre la tierra, sino sabios envenenados y corrompidos por el ideal y el sacerdote ascéticos ${ }^{8}$. No es la risa un problema que haya de ser objeto de la investigación filosófica, como pueda serlo la verdad, la historia, la naturaleza o el ser humano; es, más bien, un ingrediente del estilo filosófico de Nietzsche, una marca de su filosofía ${ }^{9}$. Yendo aún más lejos: puede ser el criterio para establecer la jerarquía entre los filósofos. Frente a la mala prensa que daba Hobbes a la risa entre los mortales, y qué decir entre las cabezas pensantes - una manifestación, las más de las veces, de personas pusilánimes y con baja autoestima $-{ }^{10}$, Nietzsche acariciaba la idea de establecer "una jerarquía de los filósofos en función del rango de su risa - hasta llegar a los que son capaces de la carcajada dorada." 11 . Una idea que, si pensamos en la seriedad y gravedad que suelen acompañar las representaciones del filósofo, hasta el punto de que en el imaginario social se consideran atributos esenciales de su naturaleza, suscitaría probablemente un rechazo generalizado por ser muy mala idea, por atrabiliaria y, por qué no decirlo, irrespetuosa. Desde Platón, la historia de la filosofía es la historia del desastre de la risa, y el filósofo un pequeño buitre enfermo de melancolía, que grita de forma espantosa cuando habla del ser y de la verdad ${ }^{12}$. Sin embargo, para Nietzsche la risa es una especie de clave de bóveda filosófica: el pensador que ríe acaricia la verdad y las livianas texturas del mundo se le muestran al filósofo cuya intentio tiene en su raíz el ánimo jocoso. La desconfianza es característica de la filosofía genuina, pues la convicción y los artículos de fe ya son impropios del pensamiento honesto ${ }^{13}$. Hay que dar, empero, un paso más, empujando así al escéptico que suscribiría lo anterior, al añadir a la incredulidad por principio el sentido del humor y la predisposición hacia lo cómico de quien conoce la relación íntima entre la risa y la filosofía. La naturaleza de los progenitores de Zaratustra determina el sí y el no que conforman su condición, a saber, la autoafirmación que emana de su vitalidad desbordante y la destrucción de todo lo declinante y dañino a la que le impulsa su demon: "¿De dónde nos viene Zaratustra? ¿Quiénes son su padre y su madre? El destino y la risa son padre y madre

\footnotetext{
Nietzsche (1988), VI, pp. 373-374.

Nietzsche (1988), V, pp. 359-361.

Cragnolini (1996), pp. 99-122.

Hobbes (1989). p. 55.

Nietzsche (1988), V, p. 236.

Philonenko (1995), p. 87.

Nietzsche (1988), III, p. 580.
} 
de Zaratustra: el destino horrible y la tierna risa engendraron a este vástago."14. Éste es un demon que ríe, que cuando se pone a escribir alumbra una obra de tono alegre y fatal como Crepúsculo de los ídolos ${ }^{15}$, y cuyo antagonista y enemigo encarnizado, que tienta una y otra vez a Zaratustra, es el demonio melancólico.

Risa y filosofía se entrelazan y se convierten en inseparables en el decir de Zaratustra. Dejaremos de lado, aunque sin olvidarlas, la dimensión fisiológica, psicológica y social de la risa ${ }^{16}$ para centrarnos en su elucidación como gesto que expresa una actitud filosófica compleja. Su complejidad se deriva de los sentidos que encierra, imbricados de un modo tal que dificulta su análisis. En cualquier caso, la risa como gesto distintivo de Zaratustra se muestra como signo, síntoma y medio de esa actitud filosófica que, a su vez, para Nietzsche, es síntoma de las fuerzas y afectos de la forma de vida que filosofa. Ese peculiar animal llamado "hombre" es el único que ríe y construye filosofías, y la razón se encuentra en el hecho de que es el que más sufre porque tiene conciencia y precisa de un sentido que justifique su sufrimiento: "Quizá yo sé muy bien por qué solo el hombre ríe: sólo él sufre tan profundamente que tuvo que inventar la risa. Es justo que el animal infeliz y melancólico sea el más jovial."17. La morfología de la voluntad de poder que propone Nietzsche ${ }^{18}$ señala que lo característico de esa voluntad en el homo sapiens estriba en que éste, a diferencia de los otros seres vivos, necesita una meta; en que el querer humano, como contrapartida del sufrimiento, exige un sentido sin el que difícilmente podría seguir queriendo. La risa activa, que no es meramente un fenómeno muscular que responde a estímulos o agentes externos, sino que implica procesos psicológicos de orden afectivo y cognitivo, tiene esa función compensatoria ante el miedo, la angustia o el sufrimiento de nuestra existencia. La risa alivia y nos hace la vida más soportable, como de forma análoga lo hacen las concepciones del mundo o, dicho de otro modo, los sistemas de creencias. Sin embargo, la risa significa más cosas y, desde luego, la de Zaratustra sobrepasa con mucho esa función paliativa, tantas veces sospechosa de conservar y reproducir la enfermedad de cuerpos y almas. Nietzsche nos explica por qué los seres humanos ríen, pero esto no es lo más importante: 1o decisivo es, en primer lugar, quién se ríe y cómo lo hace, de qué es síntoma, en definitiva, esa risa; en segundo, de qué es signo esa risa, es decir, qué conocimiento expresa; $y$, por último, contra quiénes se dirige la risa entendida ahora como arma destructiva o, dicho en términos más moderados, como herramienta de la crítica. El animal hombre se ríe de muchas maneras, y no todas significan lo mismo ni tienen el mismo valor, como ejemplarmente nos enseña esa caja de risas que es Así habló Zaratustra.

La risa de Zaratustra expresa una actitud filosófica ${ }^{19}$. Por "actitud filosófica" entendemos el modo como se hace filosofía, es decir, la predisposición del filósofo que regula sus actos y que condiciona en términos generales los límites y el alcance de su discurso. En consecuencia, no existen tantas filosofías como filósofos, sino tantas como actitudes filosóficas aparezcan en una determinada época histórica o

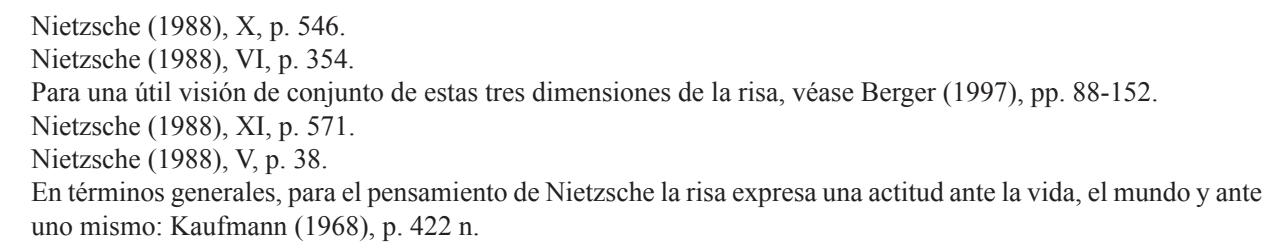


en la totalidad de la historia de este saber. En este sentido, podemos hablar, como hace el propio Husserl, de la fenomenología como una "actitud intelectual" opone a la actitud natural y que caracteriza tanto lo que en propiedad puede llamarse "filósofo" como el peculiar sentido de aquello a lo que se dirige y que constituye el objeto de su investigación, el "fenómeno"21. También podemos mentar aquí la actitud crítica que distingue a la teoría crítica de la tradicional, según los planteamientos de Horkheimer: una actitud filosófica que reconoce la naturaleza social del conocimiento como su condición de posibilidad y la intentio práctica de todo filósofo y toda filosofía si se tiene en cuenta el presupuesto de la inseparabilidad de la teoría y la praxis $^{22}$. Fuera de las etiquetas habituales, nombramos la actitud filosófica de Nietzsche como "cuidado de la vida". La risa de Zaratustra expresa ese cuidado, lo que quiere decir que nos muestra, como signo, un "saber de la vida", como síntoma, el "estado" en que se encuentra la vida, y, como herramienta crítica, la "protección de la vida". Es oportuno recordar en este momento que cuando Nietzsche utiliza la palabra "vida" en un sentido filosóficamente relevante, siempre la está pensando bajo la determinación de la oposición salud/enfermedad: "vida" es siempre vida sana o enferma o vida que pierde o recupera la salud o vida que lucha por su salud conquistándola y también perdiéndola a cada momento. Consideraremos en lo que sigue los tres significados filosóficos de la risa de Zaratustra ${ }^{23}$.

\section{La risa como signo de sabiduría}

Una sabiduría de la vida expresa la risa de Zaratustra, una sabiduría dionisíaca a la que Nietzsche le dio un nombre y le dedicó un libro: la gaya ciencia, la ciencia jovial. Jovialidad puede significar varias cosas: alegría, buen humor, divertimento y un estado de ánimo que predispone de forma irresistible a la risa y respecto del cual la risa es su más propia manifestación. Un conocimiento animado por un temple jovial se recoge y se despliega bajo principios muy distintos y contrarios de los de una ciencia melancólica, que tiene a la tristeza por dama de compañía y en la impotencia de la razón el motivo de su amargura ${ }^{24}$. A Nietzsche le repele el anhelo y el saber de la vida recta, a no ser que la rectitud de la vida se perciba como su intensificación en términos de crecimiento de la vitalidad y el poder. Conocer es para Nietzsche interpretar, e interpretar es introducir un sentido en aquello que en sí mismo no lo tiene. A los sabios que todavía se piensan movidos por la voluntad de verdad hay que abrirles los ojos diciéndoles que su entrega abnegada y pura en pos del conocimiento verdadero es otra cosa muy distinta, es la voluntad de hacer pensable lo existente, sometiéndolo de este modo, es voluntad de poder ${ }^{25}$. Desconectar el conocimiento de la verdad, como muy bien ha visto Foucault ${ }^{26}$, significa reconocer la voluntad de verdad

$20 \quad$ Husserl (1982), p. 33.

21 Husserl (1993), p. 7.

22 Horkheimer (2000), pp. 41-42.

23 Así habló Zaratustra es el lugar donde la risa, como marca de estilo filosófico, alcanza su máxima expresión y sentido, su plena madurez. Su función crítica y su condición de señal de una filosofía creadora aparecen perfectamente trabadas y desarrolladas en los discursos de Zaratustra, el filósofo que ríe: véase De Santiago Guervós (2004), pp. 544-550.

24 Adorno (1987), p. 9.

25 Nietzsche (1988), IV, p. 146.

26 Foucault (2015), pp. 35-37. 
como una modalidad de la voluntad de poder, significa, dicho con otras palabras, que con el conocimiento se hacen y consiguen muchas cosas, pero no se alcanza la "verdad" tal y como la han pensado la mayor parte de los filósofos. Esa verdad sólo existe como ficción, como invención, lo cual en principio no la invalida por ser tal. Sin embargo, hay otras verdades, no más verdaderas que la "verdad objetiva", pero sí "mejores", que pertenecen a quienes saben que, si interpretar se entiende así, el mundo, que es aquello a lo que se inyecta el sentido, no es algo diferente y separado de la interpretación que lo revela. No hay, pues, mundo verdadero (ni aparente, habría que añadir, como lo hace Nietzsche en Crepúsculo de los ídolos ${ }^{27}$ ), sino múltiples interpretaciones, y el juego entre ellas dispone lo verdadero en un sentido u otro. La ciencia jovial, un saber de la vida que se reconoce como un saber "superior" porque se atribuye la facultad de imponer nuevas reglas en el juego del conocimiento, es una perspectiva en la que el mundo, la verdad y el filósofo se vinculan bajo los auspicios de lo cómico y de la risa. No hay perspectivismo sin la carcajada que produce la seriedad pretenciosa del que se llena la boca con la palabra "verdad", ni lo hay sin la risa que suscita la sorpresa desagradable de quien, buscando afanosamente la verdad, acaba por descubrir que esa verdad divina no existe, ni lo hay sin la sonrisa ante el nuevo creyente positivista que abraza la ciencia y no se percata de que ese abrazo también está impulsado por la voluntad de verdad y el ideal ascético. Es esta una ironía de rango superior, como ya queda escrito en Sobre verdad y mentira en sentido extramoral ${ }^{28}$, el acontecimiento en virtud del cual el animal humano toma consciencia de que el momento más mentiroso de ese fugaz instante del tiempo cósmico que es la historia universal, es cuando inventó el conocimiento y con ello se creyó señor, aunque de forma vicaria, del universo.

La vis cómica del saber de Zaratustra, que somete la creencia de los filósofos del canon de la historia de la filosofía en el carácter divino de la verdad a la sátira del que ha visto más lejos y ha explorado territorios más profundos, nos revela paradójicamente un mundo que carece de profundidad porque queda privado de todo fundamento. "Caos" es el nombre de su único atributo, una marca de superficie cuya determinación viene dada por lo que significan las palabras "devenir", "azar", "necesidad" e "inocencia". Caótico es el mundo sin trasmundo, lo que antes que nada quiere decir: sin finalidad. Lo que carece de finalidad no puede ser un cosmos, la forma por excelencia en que comparece a presencia el mundo para el espíritu de la pesadez. Sin finalidad e inocente se muestra el mundo al saber de Zaratustra: si todavía tiene sentido hablar del "Ser", entonces hay que tener presente su levedad y su indiferencia monstruosa respecto al ser humano. Porque es equívoco en la medida en que el mundo se concibe infinito pues infinitas e irreductibles son sus interpretaciones, su ligereza lo enfrenta a las pretensiones de aquellos que lo lastran con pesadas cargas llamadas "razón" y "verdad", "bien" y "mal", "culpa" y "castigo". La levedad y superficialidad del ser es insoportable para el saber de los trasmundanos, pero no para la sabiduría de Zaratustra, que no sólo conoce el absurdo eterno de la existencia, sino que amorosamente la abraza riendo y bailando, pero también sufriendo, porque el ser sólo es inteligible, en la medida en que lo sea, como vida, y a ésta y a todo lo viviente le acompaña el dolor con la misma inexorabilidad que las sombras a los cuerpos iluminados por el sol. Lo que hace el pastor con la serpiente

Nietzsche (1988), VI, p. 81.

28 Nietzsche (1988), I, pp. 875-876. 
en el célebre apartado de Asi habló Zaratustra titulado "De la visión y el enigma", simboliza la asunción e incorporación plena de este pensamiento terrible signado con la expresión "eterno retorno" y su consecuencia para quien pasa la prueba más exigente y difícil de todas: su transfiguración en un iluminado que ríe con una risa jamás oída hasta entonces ${ }^{29}$. La sabiduría de Zaratustra, que experimenta hasta el final lo cómico del mundo y de la vida, supone poner en suspenso su espesor, rebajando así su sustancia y liberando a la subjetividad de la carga que se le atribuye ${ }^{30}$. Rotas las cadenas que le maniataban y lograda su condición de espíritu libre, la consciencia de la incongruencia omnipresente y radical que domina vidas y cosas se abre paso en el espíritu de Zaratustra, generándole un estado de ánimo que supera la intensa y profunda aflicción que produce la repetición del absurdo mediante la risa redentora que lo afirma. Muertos todos los dioses, sólo nos queda la tierra ligera y la risa tempestuosa que se cuela por todos sus rincones ${ }^{31}$, comenzando por los recovecos de nuestros cuerpos y nuestras almas: " $i t a l$ vez porque ya nada de hoy tiene futuro, precisamente nuestra risa todavía lo tenga!"’32, exclama Nietzsche.

\section{La risa como síntoma de una forma de vida}

Hay risas de muchas clases, y de esto nos da una buena prueba Así habló Zaratustra. Demos dos muestras. Primera: si nos fijamos en el "Prólogo", el eremita con quien se encuentra Zaratustra en su bajada al valle ríe - una risa "idiota" - cuando alaba a Dios con su canto ${ }^{33}$, y el pueblo a quien Zaratustra predica el superhombre se burla riéndose de él y le grita diciéndole que se quede con su superhombre y que les dé el último hombre. Su risa rezuma odio y en ella "hay hielo"34. Segunda: si centramos la atención en el capítulo del Libro IV dedicado a los hombres superiores, que abandonan a Zaratustra por un asno al que terminan adorando, pues, como le dice el viejo Papa, “ ¡Es mejor adorar a Dios así, bajo esta forma, que bajo ninguna forma!" 35 , es fácil comprender que emiten una risa patética producto de su cobardía y debilidad. Frente a estas risas, Nietzsche describe con metáforas los matices de la risa de Zaratustra: es el único que ríe y que está elevado a la vez, es una risa de altura ("Del leer y el escribir"36); es una risa que mata ("Del leer y el escribir"37 y "La fiesta del asno"38); emana de la belleza, es una risa bella ("De los virtuosos"39); es similar a la de su "perro de fuego", una risa como una nube colorida que procede del corazón

29 Nietzsche (1988), IV, pp. 201-202.

30 En la exposición de los principios que distinguen los géneros de la poesía dramática, Hegel nos señala el desfondamiento del mundo y la correspondiente liberación de la subjetividad como el humus característico de la comedia. Sobre este asunto, Hegel y Nietzsche se encuentran muy próximos: véase Hegel (2011), p. 859.

31 Para una conexión entre la risa como rasgo de la consciencia moderna de la muerte de dios y su significado literario (M. Bajtin), vinculado a la génesis de la novela, y filosófico (Nietzsche), vinculado a una ciencia jovial, véase Quesada (2001), pp. 161-173.

32 Nietzsche (1988), V, p. 157.

33 Nietzsche (1988), IV, p. 13.

Nietzsche (1988), IV, p. 21.

Nietzsche (1988), IV, p. 390.

Nietzsche (1988), IV, p. 49.

Ibidem.

Nietzsche (1988), IV, p. 271.

Nietzsche (1988), IV, p. 120. 
de la tierra ("De los grandes acontecimientos" ${ }^{40}$ ); es una risa victoriosa, como el soplo de un fuerte viento que barre todo cansancio de muerte ("El adivino" ${ }^{11}$ ); en su mano está alcanzar la risa suprema del pastor transfigurado, y puede ser, entonces, una risa sobrehumana ("De la visión y el enigma" espectáculo bochornoso de los apóstatas que se vuelven otra vez piadosos, siendo así como Zaratustra puede morirse de risa, al igual que les pasó a los viejos dioses, cuando escucharon a uno decir que hay un solo Dios y que no debía tener a otro junto a él ("De los apóstatas" es una risa malvada, aunque santificada por su querer ("Los siete sellos [o la canción del Sí y del Amén]" ${ }^{44}$ y "La ofrenda de la miel"45); y Zaratustra, el mayor de los espíritus libres, posee una risa tormentosa que ciega con el polvo que levanta a todo pesimista y quisquilloso ("Del hombre superior" ${ }^{2}$ ). Más allá de estas características, y situándonos en un estrato más profundo, como gesto de una actitud filosófica la risa ya no es ahora signo de una sabiduría, sino síntoma del estado en que se encuentra la forma de vida que ríe. ¿De qué es síntoma la risa, de la salud o la enfermedad, de la elevación o del declive de la vida, de la fortaleza o la debilidad, de la cualidad afirmativa o negativa de la voluntad del que ríe? El criterio para valorar la risa de Zaratustra, la risa del filósofo y la risa en general está contenido en esa pregunta y no es distinto del que propone Nietzsche para juzgar el valor de una filosofía, incluyendo su valor de verdad. Una estimativa de este tipo focaliza su atención en quién se ríe, de la misma manera que en el juicio de valor sobre las filosofías lo relevante no es su "qué", sino el "quién" filosofa, es decir, cómo son las fuerzas vitales que organizadas como cuerpo y espíritu toman la palabra y se expresan filosóficamente. El Prólogo añadido a la segunda edición de La gaya ciencia deja muy claro este punto crucial de la filosofía de Nietzsche: la valoración de toda filosofía discurre por un plano "psicológico-fisiológico"-empleamos sus propios términos-que interpreta el pensamiento filosófico como síntoma de estados saludables o valetudinarios y lo estima en función de si expresa la salud o la enfermedad y de si contribuye a satisfacer las necesidades de un cuerpo sano o uno enfermo ${ }^{47}$. Así la filosofía, así la risa. La risa es gesto (síntoma) de una actitud filosófica que a su vez es síntoma de una vida sana o enferma. En este respecto, la pregunta apropiada ante la risa de Zaratustra es la que formula ante la filosofía el médico o el psicólogo aludido por Nietzsche en el mencionado Prólogo: ¿quién o qué es lo que ríe en la risa de Zaratustra?

Como síntoma de su cuerpo y de su espíritu, en la risa de Zaratustra comparece a presencia la sobreabundancia de vida, el júbilo desbordante de una salud óptima y la potencia expansiva de una gran fortaleza. Su risa expresa o tiende a expresar un gozoso "sí" a la existencia sin condiciones, la plena aceptación, sin hipoteca alguna, de su vida y, con ello, de la vida en su totalidad, pues el instante que, como acontecimiento, significa Zaratustra está por fuerza anudado con todos los instantes que han sido y con todos los que serán. La "carcajada dorada", que ocuparía el

\footnotetext{
Nietzsche (1988), IV, p. 170.

Nietzsche (1988), IV, p. 175.

Nietzsche (1988), IV, p. 202.

Nietzsche (1988), IV, pp. 229-230.

Nietzsche (1988), IV, p. 290.

Nietzsche (1988), IV, p. 298.

Nietzsche (1988), IV, p. 367.

Nietzsche (1988), III, pp.347-349.
} 
lugar más alto en la jerarquía de las risas de los filósofos imaginada con malicia por Nietzsche y que podemos, sin mucho temor a equivocarnos, atribuírsela a Zaratustra, es el mejor de los síntomas, porque expresa la suprema afirmación de la vida. La carcajada burlona y resplandeciente y, cómo no, malvada, que Zaratustra lanza desde lo alto de su montaña y que pretende, en virtud del cebo irresistible contenida en ella, pescar a los peces humanos más hermosos en las cenagosas aguas del valle, es símbolo del amor fati $^{48}$ encarnado en el que así ríe. De la suprema voluntad afirmativa que dice sí una y otra vez a la vida queriendo su repetición tal cual es y en su integridad, con sus lotes de placer y dolor, de pena y alegría, la risa de Zaratustra es el más perfecto de sus síntomas.

¿No es síntoma, entonces, la risa de Zaratustra de ninguna penumbra en su espíritu? ¿Sólo de una luz cuya intensidad ha de cegar a todos los que no se proyecten al menos un par de escalones por encima de lo humano? ¿No remite esa risa, en definitiva, a potencias negativas de las que también sería síntoma? La risa de Zaratustra también expresa el duro e inmisericorde "no" que grita tantas veces su corazón. En tanto que no sólo representa el anhelo de la gran salud, sino también una voluntad de destrucción de todo poder enfermo, esta risa es síntoma del gran desprecio que se deriva forzosamente de la afirmación incondicional de la existencia. Zaratustra no sólo es el maestro del eterno retorno, sino también el del gran desprecio de toda humanidad que no trabaje para su autosuperación. Cuanto más fuerte sea el poder y la influencia de la letanía del adivino ("¡itodo está vacío, todo es igual, todo ha pasado ya!"49), el gran tentador de Zaratustra para que cometa su último pecado, más intensa y fuerte ha de ser la risa que desprecia desde el sí a la vida. A la tentación de la compasión por el ser humano hay que oponer el desprecio de una risa que lo contempla desde una altura de seis mil pies y cuyo ardoroso afán es el de contribuir al ocaso del tipo de hombre enfermo que hasta ahora ha prevalecido sobre la tierra, un anhelo movido por la esperanza de que ese ocaso querido pueda ser también tránsito hacia otra humanidad en la que impere todo lo que significa para Nietzsche la gran salud. La palabra "superhombre" mienta precisamente la anticipación de Zaratustra de esa otra época que puede alumbrar el ocaso de esta humanidad. La risa de Zaratustra es síntoma de dos pasiones de su espíritu que son inseparables, la que dice "sí" y la que dice "no", o lo que es lo mismo, la que promueve la incondicional autoafirmación de la vida, propia de la salud recuperada, o la que impulsa el gran desprecio que merece todo lo que hace del ser humano un animal pusilánime y enfermizo que sólo aspira a su pequeña felicidad. El concepto de "pathos de la distancia" $" 50$ enlaza en su interior de forma precisa estas dos pasiones de ese filósofo que ríe llamado "Zaratustra". Este pathos impone un orden de rango que establece diferencias de valor, cada vez más grandes y numerosas, entre los seres humanos de acuerdo al grado de afirmación (salud) y de negación (enfermedad) de la vida que representan. En la pasión que instaura distancias están comprendidos todo el amor y la repugnancia de Nietzsche por el ser humano, cuyo síntoma por excelencia es la risa de Zaratustra.

48 No sólo aceptar la necesidad, sino quererla, querer lo que uno es en su totalidad y para siempre en virtud de la repetición del eterno retorno, tal cosa es el amor fati, la suprema afirmación de la vida: véase Nietzsche (1988), V, p. 297.

$49 \quad$ Nietzsche (1988), IV, p. 174.

50 Nietzsche (1988), V, pp. 205-206. 


\section{La risa como medio de destrucción}

En dos lugares de Así habló Zaratustra se alude al poder mortífero de la risa: en el primero, Zaratustra invoca a la risa para matar al espíritu de la pesadez ${ }^{51}$; en el segundo, es el más feo de todos los hombres quien afirma haber aprendido del maestro que la persona que ríe es quien quiere matar desde lo más profundo ${ }^{52}$. Entramos en el terreno del último aspecto de la risa de Zaratustra que, entendida como gesto de una actitud filosófica, ya no es signo ni síntoma, sino señal del objetivo a batir. Se trata de la risa como poder destructivo y como medio del cuidado de la vida para salvaguardarse de todo lo que para el Nietzsche de los últimos años significa el término "decadencia".

No son ni el mercado ni el Estado los centros en torno a los cuales giran todas las cosas. El primero es el lugar de los muchos, del ruido y de los comediantes que gozan de la fama que les reconoce el "pueblo", que nada sabe de lo que es verdaderamente grande $^{53}$. El segundo es el monstruo frío por antonomasia, que sólo sabe mentir y que actúa como una maquinaria irresistible imponiendo su fuerza ${ }^{54}$. Se equivocan, a juicio de Zaratustra, quienes piensan que en ellos reside el poder que sostiene y pone en movimiento a todas las cosas. La economía y la política son servidores de otros amos, pues carecen de espíritu; y si se convierten en amos, principia el reino del último hombre. Nada tienen que hacer, mostrándose impotentes, con el ámbito del sentido, el centro sobre el que sí giran silenciosamente todas las cosas, el aliento que hace mover todos los engranajes sociales y políticos. Este lugar es el de los "valores", en concreto es el dominio de los creadores de valores, respecto a los cuales sí giran silenciosamente el mundo y todo lo que contiene. Ahora bien, los creadores de valores, señores de la tierra, instauran el orden dotando de significado a las palabras "bueno" y "malo" e inscribiéndolas en sólidas tablas que fundamentan la existencia de los seres humanos porque la dotan de sentido. Lo que más ama Zaratustra es su voluntad, porque sólo la voluntad es creadora de valores, y sólo el que los crea sabe realmente en qué consisten. Zaratustra baja de la montaña al valle porque va al encuentro de los hombres para hacerles un regalo gracias a su virtud pródiga. Es una nueva tabla, no la reescritura de otras anteriores, una nueva tabla hecha del material más duro -denominado por Nietzsche "transvaloración"- sobre el que se inscribirán nuevos valores. Mas para crear nuevas tablas y conseguir que imperen, hay que destruir las que están vigentes. Todo creador es un aniquilador, por ello lo bueno es inseparable de lo malo: para poder crear hay que poder destruir. Para Zaratustra, el fundamento en que se ha sostenido todas las viejas tablas hasta ahora existentes es la Carthago que hay que arrasar. Carthago delenda est, lo que significa: hay que derribar la autoridad que ha escrito las viejas tablas de valores. Para ello, un arma poderosísima, quizá la más terrible, es la risa. Así lo piensa, al menos, Zaratustra: su risa es el viento y la tormenta destructores de las viejas autoridades y las enmohecidas tablas que escribieron.

Como medio protector de la vida, la risa es la dinamita adecuada para demoler toda autoridad dañina para ella. La autoridad no es el poder: es la instancia que

\footnotetext{
Nietzsche (1988), IV, p. 49.

Nietzsche (1988), IV, p. 392.

Nietzsche (1988), IV., pp. 65-66.

Nietzsche (1988), IV, pp. 61-64.
} 
legisla creando los valores sostenedores del poder. De nuevo es pertinente recordar en este momento que la forma que toma la voluntad de poder en el ser humano requiere en todo momento como condición de su existencia una meta que confiera sentido a su querer: "El hombre puso en las cosas valores con los que conservarse, - ¡antes de nada creó el valor de las cosas, creó un sentido para el hombre! Por eso se llama a sí mismo ‘hombre', esto es: el que valora." ${ }^{55}$ Si por poder entendemos la capacidad de dominar que tiene una voluntad sobre otras -una relación en la cual unos mandan y otros obedecen-, esa capacidad sólo es efectiva en la medida en que el que la ejerce esté investido de la pertinente autoridad. Como muy bien nos indica H. Arendt, no es el engaño, la persuasión ni la coacción el baluarte de la autoridad, sino el reconocimiento por parte de aquellos a quienes se les pide obedecer ${ }^{56}$. Los que mandan sólo pueden mandar de forma legítima si los otros sometidos a su mando están dispuestos - no forzados- a obedecer, y sólo están dispuestos a ello si al poderoso que manda se le reconoce su autoridad para hacerlo. Si menoscabamos la autoridad, debilitamos la voluntad de poder que la precisa para su imperio, pues sólo a través de la interpretación puede aquélla ejercer su dominio sobre otras voluntades de poder. El creador de valores es el que fija el criterio del bien y del mal y de la verdad, disfrutando por eso de la autoridad que conserva y permite el crecimiento del poder. Los que han ocupado y todavía ocupan las cátedras de la virtud y las del saber, que han dictado y perpetuado los valores nihilistas regentes de los destinos de la humanidad, son el objetivo principal de la risa de Zaratustra. Su risa puede matar al espíritu de la pesadez porque disuelve el poder espiritual ${ }^{57}$ que posee y garantiza su dominio. No es de extrañar entonces que Zaratustra nos exhorte a reírnos de la autoridad que tanta demencia ha permitido durante milenios:

Y yo les mandé derribar sus viejas cátedras y dondequiera que se hubiera sentado aquella vieja presunción; les mandé reírse de sus grandes maestros de virtud y de sus santos y poetas y redentores del mundo.

Les mandé reírse de sus sabios presuntuosos y de todo aquel que se hubiera sentado, haciendo advertencias como un negro espantapájaros, sobre el árbol de la vida. ${ }^{58}$

La risa de Zaratustra, como instrumento de ataque y defensa en pro del cuidado de la vida, expresa el desacato a la autoridad vigente y la intención de aniquilarla. Esta risa ácida y naturalmente malvada para los que se llaman "los buenos y los justos" y se consideran los mejoradores de la humanidad, ha de ser insumisa a cualquier pretensión de control político y social sobre ella, que ordena cuándo, dónde, cómo y sobre qué hay que reírse. Es una risa extemporánea e impertinente, que por definición ha de estar fuera de lugar y atentar contra el buen gusto socialmente establecido. De quien se carcajea en sede judicial, de quien se ríe del maestro en la escuela, de quien lo hace en las narices del patrón cuando ordena, de quien se ríe en

$55 \quad$ Nietzsche (1988), IV, p. 74.

56 Arendt (1973), p. 147. Concluye lúcidamente H. Arendt en este asunto de la autoridad de un modo que nos incumbe y que suscribimos palabra por palabra: "El mayor enemigo de la autoridad es, por eso, el desprecio y el más seguro medio de minarla es la risa." (ibid., p. 148).

57 Empleamos la noción "poder espiritual" en el mismo sentido que la usa A. Comte, a saber: "Por tanto, el poder espiritual tiene por destino propio el gobierno de la opinión, es decir, el establecimiento y el mantenimiento de los principios que deben presidir las distintas relaciones sociales." (Comte 2001, p. 258).

$58 \quad$ Nietzsche (1988), IV, p. 247. 
la asamblea a consecuencia de la sátira cruel que se hace sobre el cuerpo sagrado e inmortal del soberano, o de la parodia al sacerdote cuando oficia sus ceremonias en los lugares sagrados, de quien emite estruendosas carcajadas con el escarnio público de las costumbres imperantes..., de cualquiera de ellos podemos decir que su risa y su carcajada son las de los dementes y criminales, las de los inmorales y antisociales, merecedoras del castigo de la autoridad que preserva el orden existente, aunque sea contrario al florecimiento y crecimiento de la vida. También ésta es la risa de Zaratustra, que se pone al servicio de su voluntad aniquiladora de todo lo que condene la vida.

\section{Incipit tragoedia, incipit parodia: un modo de concluir}

¿Ha de coronar el esfuerzo del artista, y también el del filósofo, la seriedad grave o la risa, la solemnidad de la fatalidad o la parodia de la vida leve, la tragedia o la comedia? La respuesta la podemos encontrar en la crítica de Nietzsche a Wagner después de la muerte del músico, un ajuste de cuentas revelador tanto de la desolación y la repugnancia que le produjo una ópera como Parsifal, como de la admiración que, a pesar de todo, nunca dejó de tener por Wagner, el acontecimiento más importante de su vida. A fin de cuentas, tenía que salvarlo por encima de todo, incluso del mismo Wagner. ¿Y si Parsifal, en realidad, no fuera lo que parece? ¿Y si su última gran ópera fuera una broma, un asunto de opereta, una magistral parodia en la que se burla de todos y de todo, y, antes que nada, de sí mismo? Albergar esta sospecha significaba para Nietzsche seguir concediéndole una oportunidad y tener para sí mismo una débil justificación de su querencia hacia él, pues tomado en serio, Parsifal era un engendro abominable, un bebedizo compuesto de odio y rencor contra los presupuestos de la vida, contra la naturaleza, contra la sensualidad y el conocimiento; era la manifestación de la más estupefaciente y repulsiva autonegación de un artista, de la vergonzosa conversión por parte de aquel que tanto admiró a Feuerbach a lo más rancio del ideal ascético en su tiempo, a los viejos y enfermizos ideales cristianos ${ }^{59}$. Sin embargo, significa algo más relevante, a saber: que el último gran acto de un artista trágico ha de consistir en su inversión paródica mediante lo cómico, que sólo cuando de las cosas más serias de la vida somos capaces de reírnos, alcanzamos su más profundo conocimiento como filósofos, que sólo cuando nos reímos de nosotros mismos estamos en condiciones de iniciar, como el sabio, el incierto camino del autoconocimiento, que sólo, en definitiva, cuando cubrimos el destino trágico de nuestra condición humana y existencia histórica, presididas por el sufrimiento y el absurdo, con la túnica de la risa y la jovialidad, podríamos tener la certidumbre de que se ha conseguido la plenitud vital y, con ella, la más elevada afirmación de la vida.. A vueltas con Wagner, de esta forma lo escribe Nietzsche en De la genealogía de la moral: "Como decía, esto hubiera sido lo propiamente digno de un gran trágico: quien, como todo gran artista, alcanza la cumbre última de su grandeza tan solo cuando sabe verse a sí mismo y a su arte por debajo de sí -cuando sabe reírse de sí mismo." ${ }^{\circ}$.

\footnotetext{
59 Nietzsche (1988), VI, pp. 430-431.

60 Nietzsche (1988), V, p. 342.
} 
Un movimiento análogo ${ }^{61}$-el que parte de la tragedia y culmina en la comedia, o el que se inicia en la solemne seriedad ante la gravedad de la vida y termina en la risa que expresa su potente levedad y su juguetona ligereza- se produce en el "Libro quinto" de La gaya ciencia, incorporado a su segunda edición (1886) y posterior a Así habló Zaratustra. La primera edición de esa obra, compuesta por cuatro libros, termina con dos parágrafos, el 341 y el 342. El penúltimo, titulado "El peso más grave", nos ofrece la primera formulación relevante de la doctrina del eterno retorno en su obra publicada. El último, cuya rúbrica significativa es "Incipit tragoedie", se reproducirá literalmente en el comienzo de Así habló Zaratustra. En esta primera edición todo parece desembocar en la gravedad, la tragedia y el esfuerzo titánico del que sufre para asumir y querer su existencia dentro del marco de la afirmación de la vida en su totalidad. ¿No es incoherente que termine así una obra que pretende fundir sabiduría y jovialidad? Para una ciencia jovial es insoslayable el sufrimiento que anida en el corazón de la vida, pero también la alegría y el gozo que se adhieren, como la hiedra sobre la piedra, a las potencias vitales aspirantes a la plenitud. Nietzsche corrigió esta unilateralidad a favor de los componentes clásicos de lo trágico (el sufrimiento, el horror, la fatalidad, etc.) en la segunda edición de La gaya ciencia (1886), mediante el añadido de un "Prólogo" y de un "Libro quinto" imprescindibles para entender el camino abierto por Así habló Zaratustra, que recorre todo lo contenido en lo que se denomina el "pensamiento de madurez" del filósofo alemán. El paso del sufrimiento a la alegría que, sin embargo, no cancela el dolor, pues éste siempre permanece como un poso irreductible para la sabiduría dionisíaca, queda perfectamente registrado en el carácter ambivalente de la experiencia de la muerte de Dios para aquellos hijos del mañana o nacidos prematuramente que son capaces de percibir lo que entraña aquel "gran acontecimiento": no sólo la "lógica del terror" que desencadena tan cardinal deceso, en virtud del cual ha de desmoronarse todo lo que en él se había apoyado, ni más ni menos que el conjunto de la moral y la cultura occidentales, sino también, y por encima de todo para quienes son capaces de ver mejor y más allá, de vislumbrar un horizonte abierto, una nueva posibilidad para el ser humano, la travesía de un barco capitaneado por el filósofo que ya es un "espíritu libre" ${ }^{2}$. La "gran seriedad" del comienzo de la tragedia vinculada a aquel gran acontecimiento, mentada en el penúltimo parágrafo del "Libro quinto", el 382, contiene, bien es cierto, la parodia de todo lo que hasta ahora se ha considerado lo más sagrado, serio, grave y solemne, pero superpone a ese gesto burlón una renovada gravedad que no se compadece en absoluto con la risa y el baile de un espíritu libre preñado de futuro como nos ilustra la figura de Zaratustra. Por ello es necesario incluir como colofón de la obra el parágrafo 383, en el que el sombrío signo de interrogación antes indicado ha de ser iluminado, si no se quiere incurrir de nuevo en los errores de las interpretaciones ascéticas de la existencia, por "la risa más maliciosa, más vivaz, más llena de duendes" ${ }^{63}$, como así le indican, reprendiéndole, los espíritus de temple jovial que animan los lugares de La gaya ciencia. Que para este filósofo dionisíaco las disposiciones y contenidos propios de lo trágico están desde el principio entrelazados -incluso gobernados, podría decirse sin faltar a la

61 De hecho, este movimiento, el que va de lo trágico a lo cómico, puede valer como uno de los hilos que nos permiten comprender la evolución del pensamiento de Nietzsche desde El nacimiento de la tragedia a Así habló Zaratustra, pasando por La gaya ciencia: véase Ávila Crespo (2001), pp. 26-31.

62 Nietzsche (1988), III, pp. 573-574.

63 Nietzsche (1988), III, p. 637. 
verdad- por los de la parodia, la comedia y por el gesto omnipresente de la risa, marca de estilo para esta filosofía, se encuentra señalado con toda claridad al final del primer parágrafo del "Prólogo" añadido a la segunda edición de aquella obra: sí, "Incipit tragoedia", pero no es menos cierto e indudable, con todo lo que esto conlleva, que también y no de forma secundaria, "íncipit parodia" 64 .

Ante el veneno del adivino (léase: Schopenhauer), cuya cantinela ya señalada es la más perfecta expresión del pesimismo, entendido como estado de ánimo y, sobre todo, como actitud filosófica, Zaratustra dispone de un antídoto: la risa. Ante la seriedad desvergonzada y la solemnidad deshonesta del sacerdote ascético y de todos sus vástagos (por ejemplo: la totalidad del idealismo alemán, por no irse más atrás en el tiempo), Zaratustra utiliza la risa como martillo crítico que, cuando les golpea, muestra por el sonido que producen una autoridad hueca, sin nada en su interior, sin sustancia alguna. Frente a la permanente tentación del demonio melancólico que también anida en el corazón de Zaratustra, sólo dispone de un remedio para evitar que su cuerpo y espíritu enfermen: la voluntad de reír siempre desde las alturas. ¿Qué significa la risa de Zaratustra? Respuesta: sabiduría de la vida, salud de la vida y crítica de la vida contra todo lo que la emponzoña.

\section{Referencias bibliográficas}

Adorno, T.W. (1987): Minima moralia, trad. Joaquín Chamorro Mielke, Madrid, Taurus.

Arendt, H. (1973): Crisis de la República, trad. Guillermo Solana, Madrid, Taurus.

Ávila Crespo, R. (2001): "De la muerte de Dios al superhombre. El sufrimiento y la risa en el 'Zaratustra' de Nietzsche”, Estudios Nietzsche, 1, pp. 26-31.

Berger, P. (1997): Risa redentora. La dimensión cómica de la experiencia humana, trad. Mireia Bofill, Barcelona, Kairós.

Cacciari, M. (1994): Desde Nietzsche. Tiempo, arte, politica, trad. Mónica B. Cragnolini y Ana Paternostro, Buenos Aires, Biblos.

Comte, A. (2001): Primeros ensayos, trad. Francisco Giner de los Ríos, México D.F., Fondo de Cultura Económica.

Cragnolini, M. (1996): "De la risa disolvente a la risa constructiva: una indagación nietzscheana”, en Cragnolini, M. y Kaminsky, G. (eds.), Nietzsche actual e inactual, Buenos Aires, Oficina de Publicaciones del CBC, vol. II., pp. 99-122.

De Santiago Guervós, L. (2004): Arte y poder. Aproximación a la estética de Nietzsche, Madrid, Trotta.

Foucault, M. (2015): Lecciones sobre la voluntad de saber, trad. Horacio Pons, Madrid, Akal.

Hegel, G.W.F. (2011): Lecciones sobre la estética, trad. Alfredo Brotons Muñoz, Madrid, Akal.

Heidegger, M. (1954): Vorträge und Aufsätze, Pfullingen, Neske.

Hobbes, T. (1989): Leviatan, trad. Carlos Mellizo, Madrid, Alianza Editorial

Horkheimer, M. (2000): Teoría tradicional y teoría crítica, trad. José Luis López y López de Lizaga, Barcelona, Paidós.

Husserl, E. (1982): La idea de la fenomenología, trad. Miguel García Baró, Madrid, Fondo de Cultura Económica.

64 Nietzsche (1988), III, p. 346. 
Husserl, E. (1993): Ideas relativas a una fenomenología pura y una filosofía fenomenológica, trad. José Gaos, Madrid, Fondo de Cultura Económica.

Kaufmann, W. (1968): The Basic Writings of Nietzsche, New York, Modern Library.

Nietzsche, F. (1988): Kritische Studienausgabe, Berlin/New York, dtv/de Gruyter.

Philonenko, A. (1975): Nietzsche. Le rire et le tragique, Paris, Librairie Générale Française.

Quesada, J. (2001): La belleza y los humillados, Barcelona, Ariel. 